\title{
Evaluation of the effect of cooling on the microbiological quality of lamb carcasses
}

\section{Yasemin YALÇIN ${ }^{1}$, Pelin KOÇAK KIZANLIK ${ }^{2}$, Cemil ŞAHIINER ${ }^{2}$, Ergün Ömer GÖKSOY²}

Cite this article as:

Yalçın, Y., Koçak Kızanlık, P., Şahiner, C., Göksoy, E.Ö. (2021). Evaluation of the effect of cooling on the microbiological quality of lamb carcasses. Food and Health, 7(3), 179-184. https://doi.org/10.3153/FH21019

${ }^{1}$ Department of Food Hygiene and Techonology, Institute of Health Sciences, Aydın Adnan Menderes University, 09100 Aydın, Turkey

${ }^{2}$ Department of Food Hygiene and Techonology, Faculty of Veterinary Medicine, Aydın Adnan Menderes University, 09020 Aydın, Turkey

ORCID IDs of the authors:

Y.Y. 0000-0002-5376-2813

P.K.K. 0000-0002-9824-9271

C.Ş. 0000-0003-4368-4732

E.Ö.G. 0000-0001-9165-5894

Submitted: 31.10 .2020

Revision requested: 08.01 .2021

Last revision received: 13.01 .2021

Accepted: 27.01 .2021

Published online: 13.05 .2021

Correspondence:

Pelin KOCAK KIZANLIK

E-mail: pelin.kocak@adu.edu.tr

\begin{abstract}
This study aimed to determine the effects of cooling on microbiological quality of lamb carcasses. Total Aerobic Bacteria Count (TABC), Enterobactericeae counts and the presence of Salmonella spp. were investigated in accordance with the Turkish Food Codex Regulation on Microbiological Criteria and European Union Commission Regulation 2073/2005. Sampling was carried out on aseptic conditions from the surface of 25 randomly selected lambs brought to slaughterhouse. The results showed that the mean TABC were $2.24 \pm 0.087 \log \mathrm{cfu} / \mathrm{cm}^{2}$ before cooling and $2.41 \pm 0.061$ $\log \mathrm{cfu} / \mathrm{cm}^{2}$ after cooling $(\mathrm{P}>0.05)$. The mean Enterobactericeae count was $0.21 \pm 0.11 \log \mathrm{cfu} / \mathrm{cm}^{2}$ before cooling and $0.69 \pm 0.13 \mathrm{log} \mathrm{cfu} / \mathrm{cm}^{2}$ after cooling $(\mathrm{P}<0.01)$. Furthermore, Salmonella spp. were determined on 3 carcasses before cooling and one another carcass after cooling. The influence of cooling on categorisation according to the legislations presented that it could potentially improve the numbers of acceptable carcasses for TABC and Salmonella spp. Nevertheless, the results exhibited that the hygiene and cooling stage of the slaughter line must be re-evaluated in terms of $\mathrm{HACCP}$ requirements and that corrective measures/actions must be taken.
\end{abstract}

Keywords: Enterobactericeae, Cooling, Lamb carcass, Salmonella spp., Surface contamination

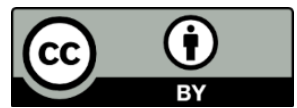

(C) 2021 The Author(s)

Available online at

http://jfhs.scientificwebjournals.com 


\section{Introduction}

Slaughter and dressing without microbial contamination of carcasses are practically impossible. The contamination originates from various sources, including fleece, viscera, equipments, other carcasses, and the hands and aprons of the personels (Hauge et al., 2011). Prerequisite programmes and the Hazard Analysis Critical Control Point System (HACCP) are applied to interrupt towards controlling carcass contamination. Fleece removal, evisceration, water washing, chilling and storage are possible critical points for the microbial contamination of carcasses during slaughter process (Milios et al., 2011).

Turkish Food Codex Regulation on Microbiological Criteria (2011), Commission Regulations (EC) No. 2073/2005 (2005) and 1441/2007 (2007) put forward microbiological performance criteria for TABC, Enterobacteriaceae and Salmonella spp. on fresh lamb carcasses. The performance criteria for TABC and Enterobacteriaceae are set out as a three class sampling plan; satisfactory, acceptable and unsatisfactory, according to the contamination level found in four different areas on the carcasses. The performance criteria vary based on whether the samples are obtained by excision or swabbing; swab samples are considered to represent only $20 \%$ or less of the microbial loads obtained by excision (EC471, 2001; O’Brien et al., 2007; Lenahan et al., 2010).

The Regulations commands for the use of TABC and Enterobacteriaceae as indicators of hygiene and faecal contamination on carcasses before cooling, however, it does not monitor the impact of cooling on carcass hygiene. Cooling is utilized as the Critical Control Point (CCP) as part of the HACCP plan to increase carcass safety (Lenahan et al., 2010).

The basis of HACCP in relation to fresh meat is that the loads of microorganisms on carcass surfaces are decreased or their growth is limited, since elimination is impossible (Sheridan, 2000). Moreover the biochemical periods and structural changes that occur in muscle during the first $24 \mathrm{~h}$ post mortem play a major role in the meat quality and are influenced by the cooling processes that carcasses are subjected to after slaughter (Fernandez and Vieira, 2012).

This study aimed to determine the levels of TABC's, Enterobacteriaceae and the presence of Salmonella spp. on lamb carcasses before and after cooling, and analysed the effect of cooling on carcass categorisation by Turkish Food Codex Regulation (2011).

\section{Materials and Methods}

\section{Materials}

In this study a total of 25 lamb carcasses, slaughtered at a private slaughterhouse located in Muğla province and stored at $2^{\circ} \mathrm{C}$ for $24 \mathrm{hr}$, were used as materials (hind shank, brisket, fore shank and neck areas).

In this study, the carcasses were chilled in conventional-commercial chillers, the temperatures measured during the cooling period was $2{ }^{\circ} \mathrm{C}$, but the air velocity and humidity of the chillers were not measured during the cooling process. In order to determine the efficiancy of cold storage, the surface and core temperatures of the carcasses were taken immediately after slaughtering process just before cooling and after 24 hours of storage period at $2^{\circ} \mathrm{C}$ by using thermometer (PCE-IR 100, Germany).

Sampling procedure was conducted as it is stated at ISO 17604 (2015). Sterile swab sponges (World Bioproduct SRDRY-G, USA) were placed in sterile stomacher bags containing $10 \mathrm{ml}$ of buffered peptone water (BPW) (Oxoid CM509, England) prior to sampling. Sampling was carried out on the hind shank, brisket, fore shank and neck areas of right half of the randomly selected lamb carcasses (total of $400 \mathrm{~cm}^{2}$ for each carcass) by using a $100 \mathrm{~cm}^{2}$ template $(10 \times 10 \mathrm{~cm})$ and sponge swabs just before cooling. Similar procedure was carried out for the left half of the carccasses after cooling. After sampling, sponge swabs were brought to the laboratory in iceboxes then the levels of TABC and Enterobactericeae, and the presence of Salmonella spp. on the samples were analysed (EC 2073/2005, 2005; TFC, 2011).

\section{Microbiological Analysis}

An additional $15 \mathrm{ml}$ of BPW were added into sterile stomacher bags containing sponge swabs from each part of the carcasses samples and brought to the laboratory. Then 2 minutes of homogenisation was carried out for each swab and homogenats from one half of the sheep carcasses were put into another stomacher bag for further homogenisation again, then serial dilutions were prepared.

In order to determine the levels of TABC and Enterobacteriaceae, plating outs were carried out on Plate Count Agar (PCA) (Oxoid CM463, England) and Violet Red Bile Glucose Agar (VRBGA) (Oxoid CM485, England), then incubated at $30^{\circ} \mathrm{C}$ for $48 \mathrm{hr}$ and at $37^{\circ} \mathrm{C}$ for $24 \mathrm{hr}$, respectively. While all of the colonies on PCA counted in order to determine the level of TABC, for Enterobacteriaceae, red colonies in $0.5 \mathrm{~cm}$ diameter or larger on VRBGA were considered as Enterobacteriaceae (ISO 4833-2, 2013; ISO 21528-2, 2017). 
For Salmonella spp. isolation, pre-enrichment was carried out by adding $225 \mathrm{~mL}$ of BPW into the homogenates. Then the samples were incubated at $37^{\circ} \mathrm{C}$ for $18 \pm 2 \mathrm{hr}$. All of the procedures followed during inoculation, incubation and identification stages were carried out as stated in ISO 6579-1 (2017). The confirmation of the results were done by using Salmonella Latex Test (OXOID FT0203A, England) kit.

\section{Statistical analysis}

For statistical analysis SPSS version 22 (USA, 2013) was used. The effects of cooling on the levels of TABC and Enterobacteriaceae were analysed by using paired $t$ test.

\section{Results and Discussion}

Strict maintenance of hygiene practices in slaughter process is important in the prevention of microbial contamination of the carcass surface in the interest of providing both meat quality and health protection (Zweifel and Stephan, 2003). The legislation suggested that microbial loads of carcass as hygiene indicators are used in slaughterhouses for evaluating the effective application of the HACCP system. TABC has been used as a general measure of the surface contamination of carcasses, whereas Enterobacteriaceae counts have been accepted as an indicator of fecal contamination (Zweifel and Stephan, 2003; Milios et al., 2011).

This study observed that the mean levels of TABC obtained from lamb carcasses before and after cooling were 2.24 $\pm 0.087 \log \mathrm{cfu} / \mathrm{cm}^{2}$ and $2.41 \pm 0.061 \log \mathrm{cfu} / \mathrm{cm}^{2}$, respectively and there was no statistical difference between before and after cooling values $(\mathrm{P}>0.05)$. Enterobacteriaceae were isolated from the carcasses both before and after cooling. When the levels of Enterobactericeae were evaluated, it was determined as $0.21 \pm 0.11 \log \mathrm{cfu} / \mathrm{cm}^{2}$ before cooling and 0.69 $\pm 0.13 \log \mathrm{cfu} / \mathrm{cm}^{2}$ after cooling, and the difference between the values was statistically significant $(\mathrm{P}<0,01)$. Cooling procedure reduced $\mathrm{TABC}$ on $52 \%$ and Enterobactericeae on $20 \%$ of the carcasses evaluated. The mean of TABC and Enterobactericeae $\left(\log \mathrm{cfu} / \mathrm{cm}^{2}\right)$ on lamb carcasses before and after cooling are shown in Table 1.
The mean of TABC determined from samples before and after cooling were somewhat lower than reported some previous studies (Lenahan et al., 2010; Hauge et al., 2011; Fernandez and Vieira, 2012). The mean Enterobactericeae observed in this study were higher than several studies (Yalçın et al., 2004; Lenahan et al., 2010), but in this study Enterobactericeae count were lower than Hauge et al. (2011) and Gürbüz et al. (2018). However, other studies have reported a higher rate of reduction in TABC and Enterobacteriaceae count on lamb carcasses than this study as a result of cooling (Gill and Jones, 1997; Yalçın et al., 2004; Hauge et al., 2011; Lenahan et al., 2010). Increases in microbial loads especially Enterobacteriaceae counts may have been due to regrowth or contamination just before or during the cooling process. The cooling can damage bacterial cells as a result of low temperatures and water activity values, but some cells have been shown to recover from these chill stresses (Yu et al., 2001; Borch and Arinder, 2002). Contamination of carcasses during cooling may have been caused by air, handling by personnel or carcasses touching each other.

Previous studies have shown different microbial loads due to the differences in sampling procedures such as sampling sites on carcass, size of sampling area. Furthermore fleece cleanliness, slaughtering procedures such as fleece removal technique and hygienic practices, may also affect the results (Hauge et al., 2011; Salmela et al., 2013). It has been considered that variations in TABC and Enterobacteriaceae levels may caused by differences in cooling parameters between studies. In this study, the carcasses were chilled in conventional chillers then the surface and core temperatures of lamb carcasses were measured before and after cooling (Table 2). The temperature measurement results were found in accordance with the temperature values specified in the regulation (Regulation of Special Hygiene Rules for Animal Food, 2011). But the other cooling parameters such as carcass spacing, air velocity and relative humidity were not recorded. On the other hand, microbial loads on carcasses were not uniform, therefore the carcas samples selected for studies could have effects on the TABC and Enterobacteriaceae counts determined (Lenahan et al., 2010).

Table 1. The mean of TABC and Enterobactericeae $\left(\log \mathrm{cfu} / \mathrm{cm}^{2}\right)$ on lamb carcasses before and after cooling

\begin{tabular}{|l|c|c|c|c|}
\hline & $\mathrm{N}$ & Before cooling $(\overline{\mathrm{X}} \pm \mathrm{S} \overline{\mathrm{X}})$ & After cooling $\left(\overline{\mathrm{X}} \pm \mathrm{S}_{\overline{\mathrm{X}}}\right)$ & Significance \\
\hline TABC & 25 & $2.24 \pm 0.087$ & $2.41 \pm 0.061$ & NS \\
\hline Enterobactericeae & 25 & $0.21 \pm 0.11$ & $0.69 \pm 0.13$ & $* *$ \\
\hline
\end{tabular}

Table 2. The mean surface and core temperature values of lamb carcasses before and after cooling

\begin{tabular}{|l|c|c|c|}
\hline & $\mathrm{N}$ & Before cooling $\left(\overline{\mathrm{X}} \pm \mathrm{S}_{\overline{\mathrm{X}}}\right)$ & After cooling $\left(\overline{\mathrm{X}} \pm \mathrm{S}_{\overline{\mathrm{X}}}\right)$ \\
\hline Surface Temperature & 25 & $25.82 \pm 0.62$ & $8.43 \pm 1.14$ \\
\hline Core Temperature & 25 & $34.10 \pm 1.53$ & $3.49 \pm 0.69$ \\
\hline
\end{tabular}


The limits for process hygiene criteria of lamb carcases given in TFC (2011) and Regulation EC 2073/2005 (2005) apply for daily mean $\log$ results at slaughterhouse level, but they can also be used for evaluation of bacterial contamination level in general. In this study, the means of TABC and Enterobacteriaceae did not exceed legal limits. To be able to determine performance criteria, TABC and the level of Enterobacteriaceae are required just before cooling by legislations. In this study, the swab criteria for lamb carcasses were calculated from excision sample values (O'Brien et al., 2007; Lenahan et al., 2010).

Based on the criteria for swabbing, 21 carcass samples were in the acceptable for TABC before cooling and 23 carcasses were after cooling. For Enterobacteriaceae, 19 carcasses before cooling and 15 carcasses after cooling were in the acceptable category. None of the samples were found in the unacceptable category (Table 3 ). When TABC was considered, the numbers of acceptable carcasses increased after cooling. However, the cooling process affected adversely the number of acceptable carcasses when Enterobacteriaceae levels were considered. The numbers of marginal carcasses decreased using the TABC and increased when Enterobacteriaceae levels were used. These results showed that cooling conditions and hygienic practices during process had the possibility to affect the extend of acceptable or unacceptable carcasses. The use of TABC and Enterobacteriaceae data to determine process control charts showing contamination rates have been used by several studies (O'Brien et al., 2007; Salmela et al., 2013). However, the same studies determined that sampling at different parts of during the slaughtering and cooling process to have an influence on the results. The process hygiene criteria for carcasses are evaluated at the end of the slaughtering, and do not regard any of the process that affect the contamination, or possible different contamination sources at the different parts of the slaughtering process. In order to evaluate slaughtering hygiene more efficiently at the slaughterhouse level, detailed information about the slaughtering process is needed in addition to the carcass microbial load before cooling.

Salmonella spp. were detected on $3(12 \%)$ carcass samples before cooling and only one carcass sample different from other Salmonella spp. positive carcasses after cooling. The presence of Salmonella spp. on carcasses indicated fecal or environmental contamination during the slaughtering process. Presence of Salmonella spp. on a different carcass after cooling could be due to the cramped hanging of lamb carcasses, personnel contamination and temperature changes during cooling stage. That is because of lamb carcasses have high water activity and $\mathrm{pH}$ values, Salmonella spp. can easily grow on the carcasses. Salmonella spp. can also adapt to conditions of temperature, $\mathrm{pH}$, and water activity beyond their normal growth range, posing great risks to food safety. Although Salmonella spp. are generally considered mesophilic in nature, some Salmonella spp. strains are able to grow in foods chilled at $2^{\circ} \mathrm{C}$ to $4^{\circ} \mathrm{C}$ and other can grow at temperatures of up to $54^{\circ} \mathrm{C}$ (Seo and Bohach, 2013). TFC (2011) and Regulation EC 2073/2005 (2005) allow that no more than 2 (c value) of 50 lamb carcasses (n value) before chill can be positive for Salmonella spp.. In addition, legislations recommend that a lower c value was used to reduce the presence of Salmonella spp.. Previous studies have shown Salmonella spp. on $1.5 \%$ on chilled carcasses (Duffy et al., 2001) and $0.25 \%$ on chilled carcasses (Lenahan et al., 2010). Kalchayanand et al. (2007) found the prevalance of Salmonella spp as $4.3 \%$ on pre-evisceration lamb carcasses. However, Salmela et al. (2013) and Gürbüz et al. (2018) did not detect any Salmonella spp. contamination on carcasses.

Table 3. The categorisation of before and after chill lamb carcasses for TABC and Enterobactericeae

\begin{tabular}{|l|c|c|c|c|c|c|}
\hline \multirow{3}{*}{ Category } & \multicolumn{3}{|c|}{ TABC (N:25) } & \multicolumn{3}{c|}{ Enterobactericeae (N:25) } \\
\cline { 2 - 7 } & $\begin{array}{c}\text { Performance criteria for } \\
\text { swabbing }\left(\log \mathrm{cfu} / \mathrm{cm}^{2}\right)\end{array}$ & $\begin{array}{c}\text { Before } \\
\text { cooling }\end{array}$ & $\begin{array}{c}\text { After } \\
\text { cooling }\end{array}$ & $\begin{array}{c}\text { Performance criteria for } \\
\text { swabbing }\left(\log \mathrm{cfu} / \mathrm{cm}^{2}\right)\end{array}$ & $\begin{array}{c}\text { Before } \\
\text { cooling }\end{array}$ & $\begin{array}{c}\text { After } \\
\text { cooling }\end{array}$ \\
\hline Acceptable & $<2.8$ & 21 & 23 & $<0.8$ & 19 & 15 \\
\hline Marginal & $2.8-4.3$ & 4 & 2 & $0.8-1.8$ & 6 & 10 \\
\hline Unacceptable & $>4.3$ & - & - & $>1.8$ & - & - \\
\hline
\end{tabular}




\section{Conclusion}

This study presented an overview to the microbial contamination of lamb carcasses before and after cooling. The levels of TABC and Enterobacteriaceae on the carcasses in this study were acceptable based on the performance criteria in legislations. However, the presence of Salmonella spp. on carcasses and the increase in The Enterbactericeae level after cooling were found to be remarkable. The variation in carcass contamination levels during the cooling process indicated that this part could be used as CCP to control contamination and improve carcass hygiene. As a result, microbiological analyzes which were carried out at the end of the slaughtering process, just before cooling, in relation to the regulations, were not sufficient for evaluating microbial quality of the carcasses. Therefore, microbial contamination levels of carcasses after cooling should be added to the performance criteria.

\section{Compliance with Ethical Standard}

Conflict of interests: The authors declare that for this article they have no actual, potential or perceived the conflict of interests.

Ethics committee approval: The authors declare that this study does not include any experiments with human or animal subjects.

Funding disclosure: This study was supported by Aydın Adnan Menderes University Scientific Research Project Coordination (Project Number: VTF-17034).

Acknowledgments: -

Disclosure: -

\section{References}

Borch, E., Arinder, P. (2002). Bacteriological safety issues in red meat and ready-to-eat meat products, as well as control measures. Meat Science, 62, 381-390.

https://doi.org/10.1016/S0309-1740(02)00125-0

Duffy, E.A., Belk, K.E., Sofos, J.N., LeValley, S.B., Kain, M.L., Tatum, J.D., Smith, G.C., Kimberling, C.V. (2001). Microbial contamination occurring on lamb carcasses processed in the United States. Journal of Food Protection, 64, 503-508.

https://doi.org/10.4315/0362-028X-64.4.503

EC/47 (2001). Commission of the European Communities: European Commission decision of 8 June 2001. Laying down rules for the regular checks on the general hygiene carried out by the operators in establishments according to Directive
64/433/EEC on health conditions for the production and marketing of fresh meat and Directive 71/118/EEC on health problems affecting the production and placing on the market of fresh poultry meat (EC/471), Official Journal of the European Communities, L165, 48-53.

EC/2073 (2005). Commission of the European Communities: European Commission decision of 15 November 2005 on microbiological criteria for foodstuffs (EC/2073/2005). Official Journal of the European Communities, L338, 1-26.

EC/1441 (2007). Commission of the European Communities: European Commission decision of 5 December 2007 amending Regulation (EC) 2073/2005 on Microbiological criteria for foodstuffs (EC/1441/2007). Official Journal of the European Communities, L322, 12-29.

Fernandez, A.M., Vieira, C. (2012). Effect of chilling applied to suckling lamb carcasses on hygienic, physicochemical and sensory meat quality. Meat Science, 92, 569-574. https://doi.org/10.1016/j.meatsci.2012.05.029

Gill, C.O., Jones, T. (1997). Assessment of the hygienic performances of an air-cooling process for lamb carcasses and a spray-cooling process for pig carcasses. International Journal of Food Microbiology, 38, 85-93.

https://doi.org/10.1016/S0168-1605(97)00087-1

Gürbüz, Ü., Telli, A.E., Kahraman, H.A., Balpetekkülcü, D., Yalçın, S. (2018). Determination of microbial contamination, $\mathrm{pH}$ and temperature changes in sheep and cattle carcasses during the slaughter and pre-cooling processes in Konya, Turkey. Italian Journal of Food Science, 30, 828839.

Hauge, S.J., Wahlgren, M., Rotterud, O.J., Nesbakken, T. (2011). Hot water surface pasteurisation of lamb: Microbial effects and cost-benefit considerations. International Journal of Food Microbiology, 146, 69-75.

https://doi.org/10.1016/j.ijfoodmicro.2011.02.003

ISO 4833-2 (2013). Microbiology of the food chain - Horizontal method for the enumeration of microorganisms - Part 2: Colony count at 30 degrees $\mathrm{C}$ by the surface plating technique. International Standard 2013, Geneva, Switzerland.

ISO 17604 (2015). Microbiology of the food chain - Carcass sampling for microbiological analysis. International Standard 2015, Geneva, Switzerland. 
ISO 6579-1. (2017). Microbiology of the food chain - Horizontal method for the detection, enumeration and serotyping of Salmonella - Part 1: Detection of Salmonella spp.. International Standard 2017, Geneva, Switzerland.

ISO 21528-2. (2017). Microbiology of the food chain - Horizontal method for the detection and enumeration of Enterobacteriaceae - Part 2: Colony-count technique. International Standard 2017, Geneva, Switzerland.

Kalchayanand, N., Arthur, T.M., Bosilevac, J.M., Brichta-Harhay, D.M., Guerini, M.N., Shackelford, S.D., Wheeler, T.L., Koohmaraie, M. (2007). Microbiological characterization of lamb carcasses at commercial processing plants in the United States. Journal of Food Protection, 70, 1811-1819.

https://doi.org/10.4315/0362-028X-70.8.1811

Lenahan, M., O’Brien, S.B., Kinsella, K., Sweeney, T., Sheridan, J.J. (2010). Assessment of lamb carcass hygiene before and after chilling at five Irish abattoirs. Food Control, 21, 313-318.

https://doi.org/10.1016/j.foodcont.2009.06.011

Milios, K., Mataragas, M., Pantouvakis, A., Drosinos, E.H., Zoiopoulos, P.E. (2011). Evaluation of control over the microbiological contamination of carcasses in a lamb carcass dressing process operated with or without pasteurizing treatment. International Journal of Food Microbiology, 146, 170-175.

https://doi.org/10.1016/j.ijfoodmicro.2011.02.023

O'Brien, S.B., Lenahan, M., Sweeney, T., Sheridan, J.J. (2007). Assessing the hygiene of pig carcasses using wholebody carcass swabs compared with the four-site method in EC Decision 471. Journal of Food Protection, 70(2), 432439.

https://doi.org/10.4315/0362-028X-70.2.432
Regulation of Special Hygiene Rules for Animal Food. Law of Authorization: 5996. Official Gazette of Publication: 27.12.2011. Nr. 28155.

Salmela, S.P., Fredriksson-Ahomaa, M., Hatakka, M., Nevas, M. (2013). Microbiological contamination of sheep carcases in Finland by excision and swabbing sampling. Food Control, 31, 372-378.

https://doi.org/10.1016/j.foodcont.2012.10.017

Seo, K.S., Bohach, G.A. (2013). Salmonella spp. In M.P. Doyle, L.R. Beuchat (Eds.), Food Microbiology: Fundamentals and Frontiers (p. 225-262). Washington: ASM Press.

Sheridan, J.J. (2000). Monitoring CCPs in HACCP system. In M. Brown (Ed.), HACCP in the meat industry (p. 203230). Cambridge: Woodhead Publishing.

https://doi.org/10.1533/9781855736443.3.203

Turkish Food Codex (TFC) (2011). Turkish Food Codex, Regulation of microbiological criteria. Law of Authorization: 5996. Official Gazette of Publication: 29.12.2011. Nr. 28157.

Yalçın, S., Nizamlığlı, M., Gürbüz, Ü. (2004). Microbiological conditions of sheep carcasses during the slaughtering process. Journal of Food Safety, 24, 87-93.

https://doi.org/10.1111/j.1745-4565.2004.tb00377.x

Yu, S.L., Cooke, P.H., Tu, S.I. (2001). Effects of chilling on sampling of bacteria attached to swine carcasses. Letters in Applied Microbiology, 32, 205-210.

https://doi.org/10.1046/j.1472-765x.2001.00886.x

Zweifel, C., Stephan, R. (2003). Microbiological monitoring of sheep carcass contamination in three Swiss abattoirs. Journal of Food Protection, 66, 946-952.

https://doi.org/10.4315/0362-028X-66.6.946 